D.O.I.: $10.3895 / \mathrm{S} 1808-04482007000200010$

\title{
DIAGNÓSTICO DA GESTÃO DO PROCESSO DE DESENVOLVIMENTO DE PRODUTOS: UM ESTUDO DE CASO NO SETOR DE EQUIPAMENTOS E PRÓTESES MÉDICAS
}

\section{DIAGNOSIS OF THE MANAGEMENT OF THE PROCESS OF DEVELOPMENT OF PRODUCTS: A STUDY OF CASE IN THE MEDICAL EQUIPMENT AND PROTHESIS SECTOR}

\author{
Camila de Araujo ${ }^{1}$, Lidiane Maria de Andrade $^{2}$, Daniel Capaldo Amaral ${ }^{3}$ \\ ${ }^{1}$ Universidade de São Paulo - USP - São Carlos - Brasil camiladearaujo@gmail.com \\ ${ }^{2}$ Universidade de São Paulo - USP - São Carlos - Brasil lidiane.andrade@gmail.com \\ ${ }^{3}$ Universidade de São Paulo - USP - São Carlos - Brasil amaral@sc.usp.br
}

\begin{abstract}
Resumo
O processo de desenvolvimento de produtos é uma fonte importante de vantagem competitiva para as empresas. A melhor forma de gerenciá-lo é por meio da abordagem de processos de negócio. Uma das barreiras para a aplicação desta abordagem é a dificuldade de se realizar o diagnóstico da situação do processo, visando a identificação e priorização das ações de melhoria. Avalia-se um caso de aplicação do modelo de maturidade de gestão de desenvolvimento de produtos que faz parte do Modelo Unificado de PDP, proposto por Rozenfeld et al em 2006. Apresenta-se os componentes deste modelo e, em seguida, descreve-se uma experiência de aplicação prática do modelo em um fabricante de equipamentos e próteses médicas. Justifica-se pela inexistência de verificações deste modelo, publicado recentemente. O método principal é o estudo de caso único, do tipo holístico, e os instrumentos de coleta são entrevista com questionário semi-aberto, observações não-participantes e análise de documentos da empresa. Como resultado, tem-se uma avaliação da aplicabilidade do modelo para a verificação do nivel de maturidade do processo de desenvolvimento de produto e sua adequação na indústria de equipamentos e próteses médicas.
\end{abstract}

Palavras-chave: Desenvolvimento do produto; processo de negócio; modelo unificado.

\section{Introdução}

O processo de desenvolvimento de produtos (PDP) é fundamental para a competitividade das empresas nos mais diversos segmentos de mercado. Entre as melhores práticas para a sua gestão, está o emprego da abordagem de processos, que visa integrar as atividades, técnicas e métodos de diferentes áreas do conhecimento como custo, qualidade, marketing, gerenciamento de projetos entre outras.

Desde o início do emprego do enfoque de processo de negócio para a gestão do 
desenvolvimento de produtos, proposto por Clark \& Fujimoto (1991), vários modelos teóricos têm sido propostos na literatura da área, contendo fases e atividades tidas como melhores práticas. Os principais são: Pugh, 1991; Wheelwright \& Clark, 1992; Cooper, 1993; Ulrich \& Eppinger, 1995; Ullman, 1997; e Baxter, 1998.

Não há dúvidas, portanto, que se trata da melhor forma de abordar a gestão do desenvolvimento de produtos. Porém, há várias dificuldades para a sua adoção. São muitas práticas, dependentes entre si de uma implantação conjunta. Os aspectos abrangente e multidisciplinar tornam difícil a identificação do nível de evolução da empresa e quais as práticas, ferramentas e técnicas deveriam ser priorizadas em cada caso específico, sendo uma outra barreira importante.

Recentemente, foi proposto por Rozenfeld et al (2006) um modelo de referência para o Processo de Desenvolvimento de Produtos, denominado modelo unificado, que visa solucionar especificamente este problema. Além de um modelo de referência do processo contendo fases e atividades, tal qual nas propostas anteriores, os autores incluem um modelo para diagnóstico da maturidade do processo de desenvolvimento de produtos da empresa com o intuito de identificar o nível em que a empresa se encontra e indicar áreas prioritárias conforme as características da empresa, seu mercado e produto. A meta dos autores é apoiar as empresas na implantação da gestão por processos do desenvolvimento de produtos.

Este modelo é fruto da síntese da experiência dos autores e resultados de pesquisas obtidos na literatura na área. Porém, não há trabalhos específicos que descrevam sua aplicação prática, avaliando-a.

O objetivo do trabalho é apresentar um caso de aplicação prática deste modelo para fins de diagnóstico. Apresenta-se uma avaliação da sua aplicabilidade especificamente para este objetivo, considerando a sua completude, facilidade de uso e resultados práticos. A meta principal do estudo, portanto, é contribuir com a evolução do modelo, identificando melhorias e avaliando o seu potencial de aplicação. Adicionalmente, o trabalho descreve as características específicas do desenvolvimento de um tipo de produto pouco estudado na literatura de PDP: ferramentas e próteses.

As bases conceituais do trabalho são a definição de processo de desenvolvimento de produto (item 2) e a descrição do modelo utilizado, o modelo de PDP unificado (3). Em seguida descreve-se o trabalho apresentando em detalhes o objetivo (4) e a metodologia de pesquisa (5). A última parte é a descrição dos resultados: a descrição da empresa (6), as atividades dentro de cada macrofase (7, 8 e 9), a análise de cada macrofase (10) e a avaliação do nível de maturidade (11). Ao final apresentam-se as conclusões do caso (12) e referências bibliográficas (13). 


\section{Processo de Desenvolvimento de Produto}

Uma das definições mais clássicas sobre processo de desenvolvimento de produtos é a de Clark \& Fujimoto (1991): "é o processo a partir do qual informações sobre o mercado são transformadas nas informações e bens necessários para a produção de um produto com fins comerciais". Esta definição pioneira marcou o início da utilização da abordagem de processos na área de gestão do desenvolvimento de produto. Até então o desenvolvimento eficiente de um produto era visto como sendo uma de responsabilidade dos setores de engenharia, desconsiderandose assim a integração entre as atividades de marketing, planejamento e introdução do produto na fábrica.

$\mathrm{Na}$ última década, porém, ela se expandiu incluindo-se atividades de planejamento estratégico (WHEELWRIGHT \& CLARK, 1993) e atividades de acompanhamento da produção e retirada do produto do mercado (ROZENFELD et al, 2006).

\section{O modelo de processo de desenvolvimento unificado}

O modelo de processo unificado foi desenvolvido a partir de conhecimentos compartilhados por uma rede de pesquisadores brasileiros denominada PDPNet, sintetizando a experiência de três grupos de pesquisa sobre gestão do desenvolvimento de produtos. Ele foi publicado recentemente na forma de livro por Rozenfeld et al (2006) e em formato de documento para consulta na web (PDPNet).

Figura 1 - Componentes do modelo unificado para o PDP

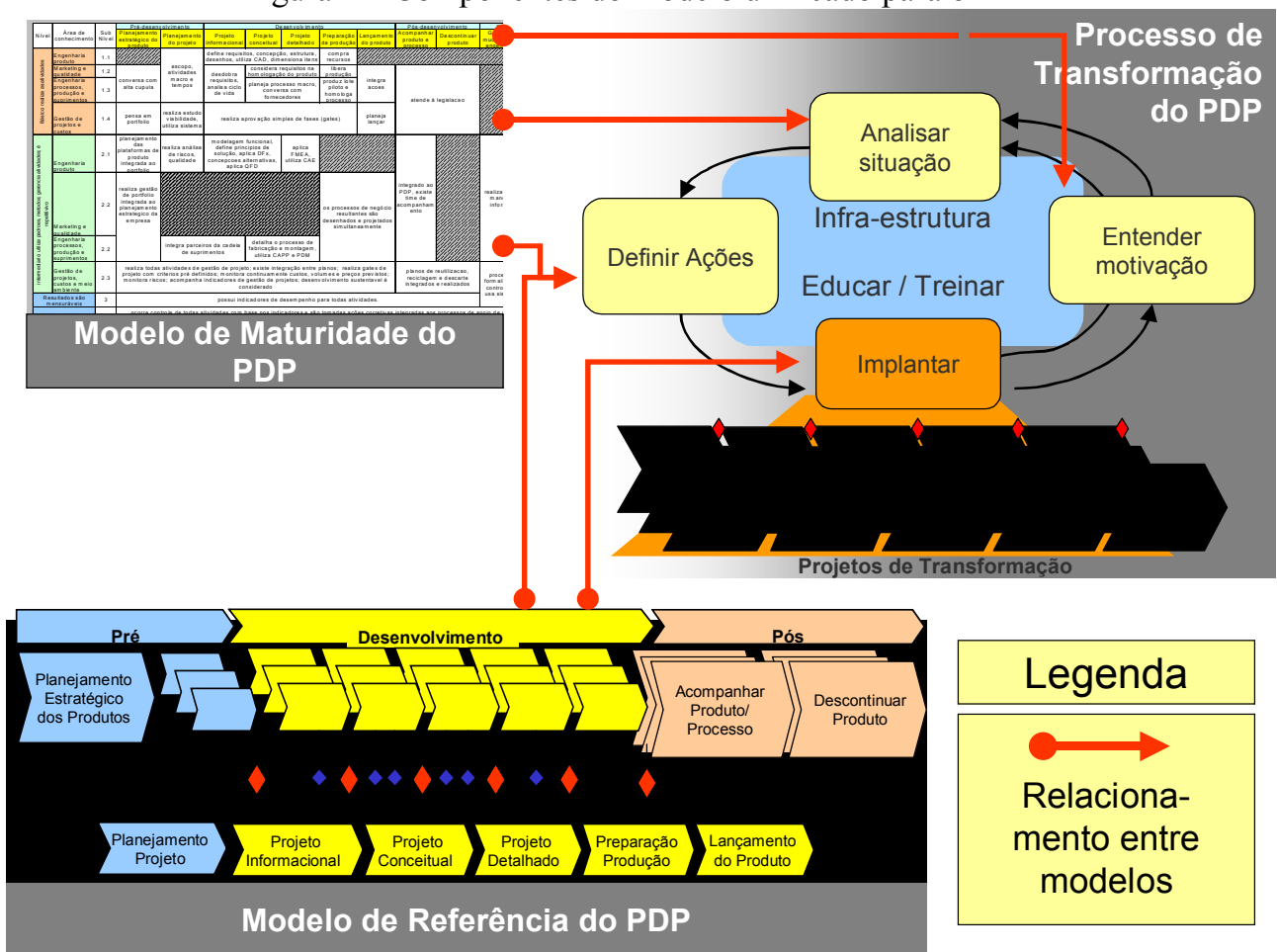


O modelo é composto por três diferentes partes distintas. O modelo de referência do PDP descreve as melhores práticas para a gestão do processo de desenvolvimento de produto, apresentando e relacionando fases e atividades às diversas técnicas e métodos disponíveis na área. O modelo de maturidade do PDP serve para apoiar a identificação do nível de evolução que a empresa se encontra. Ele descreve níveis de maturidade e apresenta quais atividades devem estar formalizadas e implementadas em cada um destes níveis. A descrição mostra, portanto, uma hierarquia de prioridade em termos de atividade na medida que os níveis mais altos só podem ser atingidos uma vez que os níveis anteriores tenham sido satisfeitos. O modelo de transformação do PDP descreve um processo estrutural para implementar as mudanças necessárias no PDP, visando a elevação do nível de maturidade, por meio de projetos de transformação. A figura 1 representa esquematicamente cada um destes modelos e mostra o relacionamento entre eles.

O modelo de referência processo é divido em 3 macrofases: Pré-Desenvolvimento, Desenvolvimento e Pós-Desenvolvimento. Cada uma das macrofases é dividida respectivamente em fases, atividades e tarefas que juntas traduzem as melhores práticas na área.

Existem atividades que acontecem em todas as fases do desenvolvimento, como a avaliação de cada fase (gates), com critérios bem definidos, monitoramento da viabilidade econômicofinanceira e documentação das decisões tomadas e lições aprendidas, gerando uma base para o desenvolvimento de futuros projetos.

- Macrofase de Pré-Desenvolvimento. O Pré-Desenvolvimento é o elo de ligação dos objetivos da empresa com os projetos desenvolvidos. Aqui entram o Planejamento Estratégico da empresa, o Planejamento Estratégico de Produtos, envolvendo o gerenciamento de portfólio de projetos e avaliações dos projetos escolhidos, verificando se esses devem ser continuados ou não.O custo das mudanças ao final de cada projeto sempre é maior do que no início do desenvolvimento, sendo assim, um bom planejamento nas fases iniciais pode gerar um diferencial competitivo para a empresa.

- Macrofase de Desenvolvimento. Dentro dessa macrofase estão as fases de projeto informacional, projeto conceitual, projeto detalhado, preparação para produção e lançamento do produto.Todas essas fases visam um detalhamento das informações técnicas, comerciais e de produção, envolvendo elementos como desenhos técnicos, protótipos, homologações, registros, parcerias com fornecedores e processos de produção.

- Macrofase de Pós-Desenvolvimento. O acompanhamento do ciclo de vida do produto é feito nessa macrofase. Aqui pode existir a preocupação com a avaliação do seu 
desempenho no mercado, sua retirada e quais processos de melhoria podem ser implementados.

- Atividades Genéricas. Existem atividades que se repetem em todas as fases do desenvolvimento, como a avaliação de cada fase (gates), com critérios bem definidos, monitoramento da viabilidade econômico-financeira e documentação das decisões tomadas e lições aprendidas. No modelo, elas são agrupadas no modelo sob o rótulo de atividades genéricas para fins didáticos.

Figura 2 - Síntese dos níveis de maturidade do modelo unificado

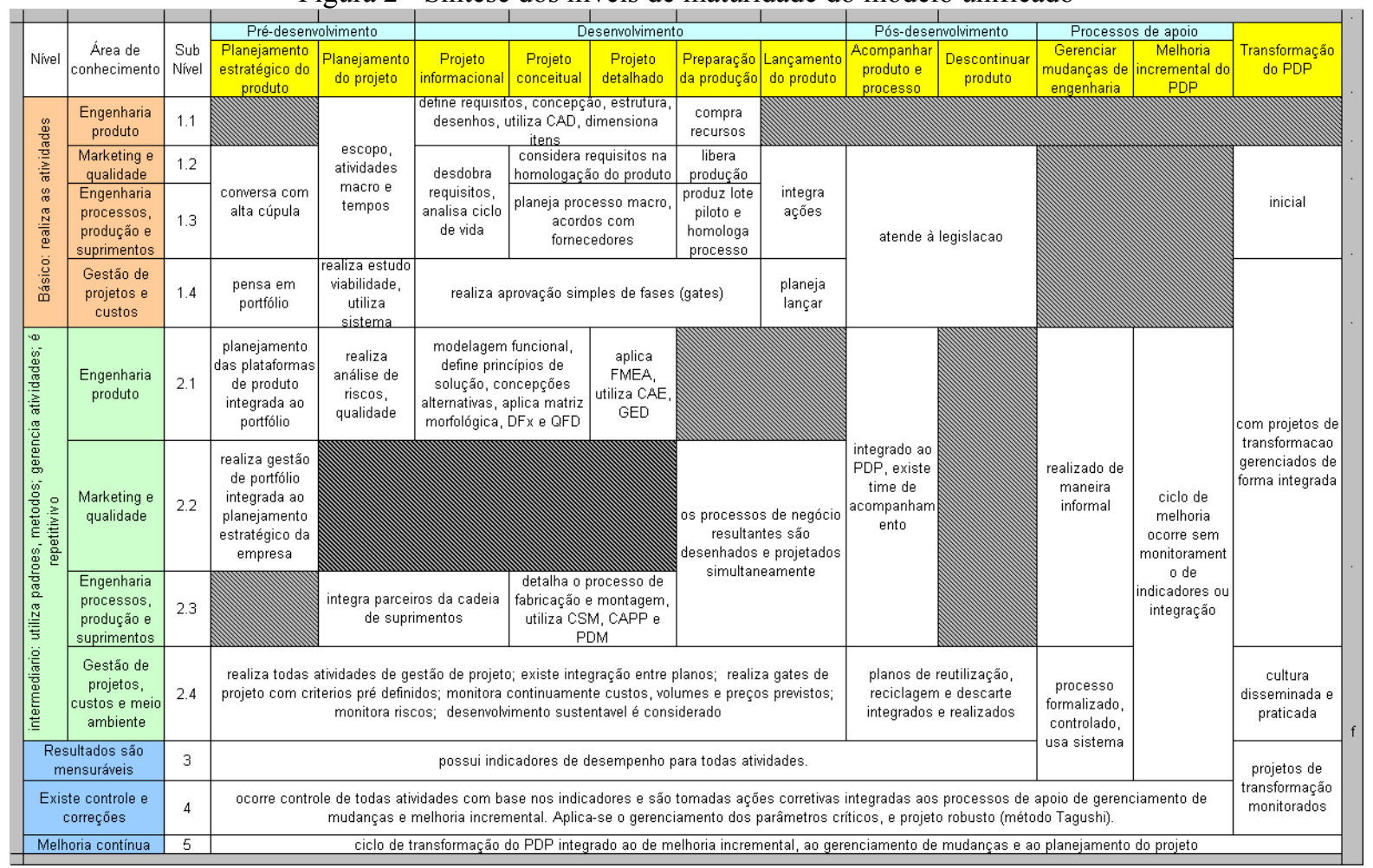

Fonte: Rozenfeld et al, 2006

O modelo de maturidade do PDP considera cinco estágios de evolução possíveis, de maneira semelhante ao CMMi, são eles:

- Nível 1 - Básico. Quando a empresa realiza de maneira sistemática um conjunto de práticas consideradas essenciais para a gestão eficiente do desenvolvimento de produtos: integra com a alta cúpula, define um detalhamento do escopo do projeto, define e desdobra requisitos, entre outras. Ele é subdividido em 4 subníveis, cada qual agrupando práticas por conjunto de áreas do conhecimento: engenharia do produto, marketing e qualidade, engenharia de processos de fabricação e gestão de projetos, custos e meio ambiente. Os níveis são identificados pelo código 1.1, 1.2 e 1.3 e 1.4. Tais áreas representam ordens lógicas de adoção na medida que são interdependentes.

- Nível 2 -Intermediário. Além de possuir as práticas, elas são padronizadas e, portanto, 
o resultado delas é previsível. No nível anterior bastava que fosse realizada mesmo que com variações. Este nível é também subdividido nos quatro níveis intermediários conforme áreas do conhecimento, denominados de 2.1, 2.2, 2.3 e 2.4 .

- Nível 3 - Mensurável. Além de padronizadas, existem indicadores para se avaliar o desempenho das atividades e a qualidade dos resultados.

- Nível 4 - Controlado. A empresa trabalha de forma sistemática para corrigir práticas cujos indicadores desviaram do valor esperado.

- Nível 5 - Melhoria Contínua. Existem processos institucionalizados para a melhoria do próprio processo de negócio, isto é, do processo de desenvolvimento de produtos, que podem ser curto ou longo prazos. Os autores propõem dois modelos. O primeiro é o "processo de melhoria incremental", um dos processos de apoio do modelo de referência do PDP. O segundo é o modelo de processo de transformação do PDP, que tem por objetivo realizar melhorias profundas e de mais longo prazo.

A figura 2 apresenta uma síntese do modelo de maturidade.

\section{Objetivo}

O objetivo geral deste trabalho é analisar a aplicabilidade deste modelo. Divide-se em dois objetivos específicos: a) Avaliar o potencial do modelo quanto à sua aplicação para a realização do diagnóstico do nível de maturidade do processo de desenvolvimento de produto; b) Verificar parcialmente a adequação do modelo na indústria de instrumentos e próteses médicas.

\section{Método}

O método de pesquisa empregado pode ser classificado como um estudo de caso único e holístico, segundo Yin(2001), durante o qual realizou-se um diagnóstico do processo de desenvolvimento de produto da empresa estudada.

Optou-se por uma empresa de pequeno porte na área de implantes ortopédicos. A escolha do segmento teve como objetivo analisar a aplicabilidade do modelo teórico em um tipo de empresa bastante distinta das comumente encontradas na literatura da área, visando a verificação da amplitude de aplicação do modelo (objetivo b).

A coleta de dados foi realizada por meio de entrevista com questionário semi-aberto, observações não-participantes e análise de documentos da empresa.

O trabalho de campo iniciou-se com análise dos documentos disponíveis sobre a empresa, o site e catálogos. Realizou-se, em seguida, uma visita à empresa, durante a qual se deu a parte principal da observação não participante. Ela se iniciou pelo chão de fábrica, departamentos de 
análises, embalagens, estocagem e administração. Durante esta visita, todos os processos de fabricação, bem como todos os documentos gerados em cada fase de fabricação, foram apresentados e devidamente detalhados. O objetivo era conhecer os produtos e tecnologias.

A entrevista foi realizada em seguida, em junho de 2006, com o Supervisor de Produção, cuja experiência na empresa ultrapassa 6 anos e inclui as etapas do processo de desenvolvimento de produtos. O roteiro de entrevistas foi desenvolvido com questões semi-abertas solicitando a descrição das etapas, atividades e ferramentas e métodos empregados no processo de desenvolvimento de produtos. Dúvidas identificadas durante a visita foram sanadas e informações sobre problemas enfrentados pela empresa idem.

Ao final, as informações foram organizadas e resumidas segundo as macro-fases do modelo unificado descritas no item 3 .

\section{A empresa}

A empresa estudada está localizada na cidade de Rio Claro/SP, foi fundada em 1992. É considerada de pequeno porte e atua no segmento de implantes ortopédicos, abrangendo áreas comerciais na América do Sul e Central. Ela possui certificação de Boas Práticas de Fabricação de Produtos Médicos - RDC 59: BPF-ANVISA. Está em processo de certificação da ISO 9001:2000, NBR-ISO-13485-2003 e Marca CE Directiva 93142.

A estrutura organizacional é funcional e a área de desenvolvimento de produto é formada por um responsável pela engenharia, três projetistas/processistas, um programador de produção e um supervisor de qualidade. A empresa fabrica um mix de aproximadamente 3.000 produtos, divididos em famílias: parafusos, placas, instrumentais, próteses. Seus produtos são padronizados e registrados pela ANVISA, pois enquandram-se na Resolução RDC No 97, DE 9 DE NOVEMBRO DE 2000 (ANVISA, 2000). As matérias-primas principais são o titânio e o aço inoxidável.

\section{Macrofase de Pré-desenvolvimento}

No desenvolvimento de um novo produto, a idéia pode surgir de dois meios:

- Buscando a necessidade do cliente, ou seja, o cliente (paciente via médico) recorre a empresa pedindo a fabricação de um produto que atenda sua necessidade,

- Proveniente da própria empresa, mais especificamente da área técnica, com auxílio de pesquisas de mercado. Essas pesquisas de mercado são geralmente feitas através da grande troca de informações entre as empresas desta área, o que justifica a quase não existência de patentes.

Assim, a única atividade formalizada da macrofase de Pré-Desenvolvimento é a concepção 
da idéia. As demais atividades como prospecção tecnológica, análise do mercado, gestão de portfólio e identificação das necessidades dos clientes são realizadas de maneira informal sem uma técnica de gestão específica ou controle das informações.

\section{Macrofase de Desenvolvimento}

\subsection{Análise do Projeto}

Primeiramente, o responsável pela engenharia é quem faz a análise da possibilidade de produção do produto. Ele tem como função verificar se é possível a realização da produção principalmente com as máquinas que a empresa dispõe.

Após a aprovação do responsável pela engenharia, a alta administração vai analisar a viabilidade econômico-financeira do produto. Desta forma, é ela que dá o aval se o produto será ou não fabricado.

\subsection{Especificação do Produto / Processo}

Esta é a primeira fase do desenvolvimento na empresa. Os projetistas, com o auxílio da ferramenta Solid Edge, desenham todo o produto. O processo de fabricação é feito também pelos próprios projetistas, que dominam o conhecimento dos processos de fabricação da empresa.

Esse primeiro desenho já é totalmente detalhado, pois como no caso de empresas deste ramo, a certificação deve anteceder à fabricação do produto, e desta forma, o desenho do produto/processo deve ser o mais detalhado possível.

\subsection{Fabricação do Protótipo}

Nesta etapa, logo após a aprovação da alta administração, com base na documentação gerada anteriormente, tem-se a fabricação o protótipo, dentro da própria empresa e utilizando os mesmos equipamentos da linha de produção.

\subsection{Testes}

Utilizando o protótipo confeccionado anteriormente, são então realizados os testes mecânicos, com parceria com CCDM (Centro de Caracterização e Desenvolvimento de Materiais UFSCar). Também são realizados os testes clínicos, geralmente utilizando parcerias médicas, com grande destaque para a área de Odontologia da Unicamp. 


\subsection{Análise de qualidade}

Ainda utilizando os protótipos, são feitos alguns testes de qualidade, todos eles utilizando parceria. Alguns exemplos de análises feitas são: tratamento térmico, eletroerosão, esterilização e usinagem, esta no caso da necessidade de uma usinagem mais pesada ou demorada.

\subsection{Homologação do produto (Registro ANVISA)}

Após a realização de todos os testes, o documento passa pela certificação ANVISA. Todo o produto deste ramo deve apresentar esta certificação que funciona como um processo de homologação citado no modelo unificado. O documento gerado contém fotos do produto, códigos, descrição do produto, bem como matéria-prima utilizada, e ainda, a descrição em português de uso do mesmo.

\subsection{Matéria-Prima}

A primeira fase do desenvolvimento é a aquisição de matéria-prima, comprada de fornecedores certificados, já que toda matéria-prima é controlada para fins de rastreabilidade.

\subsection{Parcerias}

Nesta etapa, são feitas as parcerias principalmente para usinagem (no caso de sobrecarga de máquinas), esterilização (para alguns produtos específicos), e injeção de plásticos.

\subsection{Produção}

Após a certificação da ANVISA o produto está liberado para ser fabricado. Como toda a matéria-prima já foi adquirida e as parcerias contatadas, o PCP (Programador de Controle de Produção) é o responsável por montar a ordem e verificar a disponibilidade das máquinas, ou seja, se haverá sobrecarga de máquinas. Também são realizados tratamentos como polimento e tratamentos químicos, utilizando ácido fluorídrico. Após esta etapa, são realizados testes de conformidade e funcionalidade. Tanto os tratamentos quanto os testes não são realizados por amostragem, ou seja, eles são realizados em todos os produtos, sem exceção. A partir disso, as peças são todas codificadas com o nome da empresa, lote, e demais descrições que podem ser rastreadas através de Raios-X, mesmo após o implante no paciente. Alguns produtos exigem esterilização e por isso eles são enviados a parceiros (já contatados anteriormente) para a execução do processo. Os produtos são embalados na própria empresa (exceto os que exigiram esterilização) em embalagens como sacos plásticos e caixas, de acordo com a necessidade dos produtos. Os 
produtos embalados seguem então para o estoque.

\subsection{Lançamento}

O lançamento dos produtos é feito geralmente por material impresso/ folhetos disseminados em feiras do setor e para distribuidores. Não há grande preocupação da empresa com o lançamento do produto, pois já possui um mercado bem estabelecido.

\section{Macrofase de Pós-Desenvolvimento}

No modelo empregado esta macro-fase é composta pelas fases de acompanhamento do Produto e Retirada do Mercado. Na empresa em questão é significativamente simples, pois não é feita a manutenção e nem existe assistência técnica do produto, pois os implantes são vitalícios. Apenas em ocasiões especiais há um acompanhamento do fabricante durante as cirurgias. Os instrumentais, ao contrário, apresentam tempo de vida útil. Ultrapassado o tempo de vida, deve ser descartado pelo cliente.

\section{Análise}

\subsection{Macrofase de Pré-Desenvolvimento}

O Planejamento Estratégico da Empresa é feito pela alta administração e não chega a ser divulgado para os colaboradores. Os projetos a serem produzidos também são escolhidos por eles e não foi possível obter detalhes das atividades realizadas. Segundo o entrevistado, esse processo é feito de maneira informal e não há registro de técnicas de análise de portfólio.

A empresa possui um grande acervo de projetos, com todas as especificações e documentações. Esse arquivo compõe o portfólio de projetos. Mas nenhum tipo de controle ou avaliação formal são feitos.

Podemos observar que existe uma integração informal entre o planejamento estratégico da empresa com o portfólio, mas devido ao grande número de projetos, o gerenciamento de portfólio pode gerar um melhor balanceamento entre projetos inovadores e de melhoria contínua, buscando um alinhamento direto com a estratégia da empresa, maximizando o retorno financeiro, capaz de manter a sobrevivência da empresa em longo prazo.

Uma análise SWOT (Strength, Weakness, Opportunity, Treath) também pode levantar os possíveis riscos e assim criar ações que diminuam o impacto dos riscos.

Reuniões periódicas entre membros da alta diretoria, engenharia e vendas para avaliar o posicionamento e o desempenho de seus produtos, bem como para compilar idéias de novos 
produtos poderiam criar uma diferenciação da empresa no mercado.

Outro ponto é a estrutura funcional da empresa, sem utilização de times multidisciplinares e de conceitos de gerência de projeto, apesar de existir uma certa integração na medida que quem projeta o produto projeta também o processo, sendo essa uma característica distintiva da empresa.

Um projeto tem características únicas e temporais, o que acarreta implicações no seu planejamento para aproveitar um intervalo de tempo adequado a seu lançamento no mercado.

O papel do gerente de projetos, no Pré-Desenvolvimento é importante para o planejamento do projeto, estimando os esforços necessários, a disponibilidade de recursos, análise dos prazos e assim definir o cronograma, aproveitando sua equipe da melhor forma para obter os resultados desejados.

Atualmente a empresa não adota nenhum sistema computacional para acompanhar o desenvolvimento de seus projetos, mas a utilização de um software específico de gestão de projetos visa facilitar esse trabalho devido a vários recursos como gestão das atividades, gestão do calendário e datas, dentre outros.

A gerência de projetos e os times interfuncionais ajudam a organização a obter uma visão de seus processos de negócios. Como a empresa em questão está em processo de mudanças para atender aos requisitos da certificação ISO 9000:2000, que exige uma gestão por processos, essas práticas podem trazer um maior controle de seus processos de negócios.

A análise de riscos dos projetos que serão desenvolvidos é outra atividade que pode trazer benefícios. As matérias-primas envolvidas nos processos de fabricação possuem um custo elevado, assim qualquer risco que ocorra efetivamente e envolva a matéria-prima, pode gerar um comprometimento com os custos do projeto. $\mathrm{Na}$ área de produtos médico-hospitalares também existe a questão da idoneidade da empresa fabricante, a importância da sua imagem para o mercado, já que seus produtos afetam diretamente na saúde das pessoas que necessitam deles, assim qualquer risco que possa vir a ocorrer afeta diretamente essa imagem e conseqüentemente sua posição no mercado competitivo. A análise de risco visa evitar essas situações e outras não citadas nesse texto.

\subsection{Macrofase de Desenvolvimento}

Nessa macrofase, temos o detalhamento de todo projeto, fabricação do protótipo, homologações e preparação para produção.

Algo que pode se melhor avaliado para evitar algum tipo de atraso ou problema são os treinamentos para os colaboradores desenvolverem seu trabalho. Para um novo projeto, que necessita de uma atividade na qual os colaboradores não estão totalmente aptos, pode ser programado para antes do início da produção, já que o processo de fabricação possui o detalhamento necessário. 
O software de gerenciamento de projetos também entra aqui como uma ferramenta de auxílio no monitoramento do desenvolvimento do projeto.

O planejamento do lançamento do produto pode gerar um melhor desempenho nas vendas, já que pode criar uma diferenciação dos seus concorrentes que ainda não lançaram algum produto similar.

\subsection{Macrofase de Pós-Desenvolvimento}

Nessa macrofase, a empresa apresentou o menor nível de prática. Não possui um Time de Acompanhamento para realizar as atividades de acompanhamento do produto e do processo, que englobam auditoria pós-projeto, avaliação da satisfação do cliente e monitoramento do desempenho do produto e registro de lições aprendidas.

A avaliação da satisfação do cliente não é uma atividade formalizada com critérios definidos, mas o setor de vendas realiza essa atividade, devido ao seu contato direto com o mercado consumidor, dando um retorno para as demais áreas relacionadas ao desenvolvimento de produtos.

A empresa realiza acompanhamento de determinadas cirurgias e avalia as opiniões dos especialistas na área, acabando por realizar a atividade de acompanhamento de desempenho do produto no mercado. Mas essa atividade não tem um processo definido e não é realizada para todos os novos produtos, podendo então ser considerada informal.

Para o Pós-Desenvolvimento, seria aconselhável a padronização e documentação das atividades realizadas, gerando base de análise para futuros projetos.

\section{Nível de Maturidade}

Pela avaliação das atividades do Processo de Desenvolvimento do Produto da empresa, ela deve ser classificada no Nível de Maturidade Básico 1.1. Essa classificação foi definida baseandose principalmente na macrofase de Pré-Desenvolvimento, já que não existe integração do planejamento estratégico de produtos com o PDP, e também pela ausência do planejamento por projetos, pois verificou-se que não existem equipes interfuncionais e a empresa visa apenas a produção.

Outras atividades do pré-desenvolvimento no nível básico que não foram encontradas são:

- Não há planejamento do escopo e tempos;

- Não existe conversa com a alta cúpula

- Não emprega a gestão de portfólio;

- Não planeja lançamento;

- Não possui aprovação de fases; 


\title{
12. Conclusões
}

A empresa estudada apresenta um desempenho operacional bastante satisfatório, os produtos desenvolvidos chegam ao mercado e toda a sua produção é vendida, o índice de defeitos é baixo e os clientes estão satisfeitos. Porém, a análise demonstra que há espaço para melhoria no desenvolvimento de produtos. Em especial, na elaboração e divulgação do planejamento estratégico, a gestão de portfólio, o planejamento do lançamento, dentre outras já citadas ao longo do texto, gerando assim um processo mais aprimorado do desenvolvimento de seus produtos.

A experiência com o uso do modelo demonstrou que ele funcionou como um bom guia para avaliação do nível de evolução da empresa em desenvolvimento de produtos. Note que foi possível estabelecer, através do modelo, um retrato muito bom da maturidade do PDP da empresa em um curto espaço de tempo. Uma deficiência encontrada é que apesar de existirem várias descrições para apoiar o diagnóstico, falta um guia ou instrumento único, um roteiro de questões, por exemplo, pronto para ser utilizado. No caso da pesquisa o modelo foi estudado em detalhes durante cerca de 2 meses para a elaboração do modelo.

Com relação ao segundo objetivo do trabalho, notou-se que o modelo de referência pode ser adaptado para o PDP da empresa em questão. Entretanto, ele apresenta um grande número de atividades e ferramentas, o que poderia tornar o PDP da empresa complexo. Deste modo, acreditamos que algumas poucas atividades e ferramentas, descritas anteriormente, ajudariam a melhorar o PDP da empresa criando uma sinergia deste processo com os demais, incluindo fornecedores e clientes. Isso não inviabiliza o modelo que, aliás, chama a atenção para este aspecto. Apenas, reforça o cuidado que se deve ter na sua adoção quanto a escolha criteriosa das práticas e ferramentas.

\begin{abstract}
The product development process (PDP) is an important source of competitive advantage for the companies. The best management practice is the business process (BP) approach. One of the barriers to this approach application is the difficulty to execute the diagnosis of the situation of the process, aiming the identification of the actions of improvement. Evaluate an application case of the maturity model of product development management. This is part of the Unified Model of PDP, considered for Rozenfeld et al in 2006. The paper presents the models components and, after that, describes a practical application of the model in a medical equipment manufacturer. This is justified for the inexistence of verifications of this model, published recently. The research methodology employed was a single and holistic case study. The data collection instruments are non-participant observations and document analysis. The results contain the description as well as an evaluation of the maturity level, considering the model proposed and its adequacy in the medical equipment industry.
\end{abstract}

Key-words: Product development; business process; unified model. 


\section{Referências}

ANVISA. Produzido por Ministério da Ciência e Tecnologia. Disponível em: <http://elegis.anvisa.gov.br/leisref/public/showAct.php?id=1217>. Acesso em: 06 jul. 2006.

BAXTER, M. Projeto de produto: guia prático para o desenvolvimento de novos produtos. São Paulo: Edgard Blücher, 1998.

CLARK, K. B.; FUJIMOTO, T. Product development performance: strategy, organization and management in the world auto industry. Boston, Mass.: Harvard Business School Press. 1991

CLARK, K. B.; WHEELWRIGHT, S. C. Managing new product and process development: texts and cases. New York: Free press, 1993.

CLAUSING, D. Total quality development. New York: ASME Press, 1994.

COOPER, R. G. Winning at new products: accelerating the process from Idea to launch. Readin, MA: Perseus Books, 1993.

PDPNet. Ambiente de Compartilhamento de Conhecimentos em Desenvolvimento de Produtos. Disponível em: $<$ http://www.pdp.org.br/> Acesso em 04 ago 2006

PUGH, S. Total design: integrated methods for successful product engineering. Reading, HA: Addison, 1978.

ROZENFELD, H et al. Gestão de Desenvolvimento de produtos: uma referência para a melhoria do processo. São Paulo: Saraiva, 2006.

SILVA, S.L., ROZENFELD, H. Aplicação de um Modelo de Avaliação da Gestão do Conhecimento no Processo de Desenvolvimento de Produto. In: ENCONTRO NACIONAL DE ENGENHARIA DE PRODUÇÃO (ENEGEP), 2002, Curitiba. Anais... Paraná: Associação Brasileira de Engenharia de Produção, 2002, p. 1-8.

ULLMAN, D. G. The mechanical design process. New York: McGraw-Hill International Editions, 1997.

ULRICH, K. T.; EPPINGER, S. D. Product design and development. New York: McGraw-Hill, 1995.

WHEELWRIGHT, S.C.; CLARK, K.B. Revolutionizing Product Development: quantum leaps in speed, efficiency, and quality. New York: The Free Press, 1992.

YIN, R. K. Estudo de caso: planejamento e método. Porto Alegre: Bookman, 2001.

ZANCUL, E. S.; MARX, R.; METZKER, A. Organização do trabalho no processo de desenvolvimento de produtos: a aplicação da engenharia simultânea em duas montadoras de veículos. Gestão e Produção, v. 13, n. 1, p. 15-29, 2006.

Nome completo: Camila de Araujo

Filiação institucional: Universidade de São Paulo - Escola de Engenharia de São Carlos

Departamento: Engenharia de Produção

Função ou cargo ocupado: Mestranda

Endereço completo para correspondência (bairro, cidade, estado, país e CEP): Av. Trabalhador São-

Carlense, 400, Centro, São Carlos, SP, Brasil, CEP: 13566-590

Telefones para contato: (19) 8169-2686 - (16) 3373-9433

e-mail: camiladearaujo@gmail.com 
Nome completo: Lidiane Maria de Andrade

Filiação institucional: Universidade de São Paulo - Instituto de Química de São Carlos

Departamento: Físico Química

Função ou cargo ocupado: Mestranda

Endereço completo para correspondência (bairro, cidade, estado, país e CEP): Rua 12, $\mathrm{n}^{\circ}$ 137,

Bairro do estádio, Rio Claro-SP-Brasil, CEP 13501-290

Telefones para contato:19-81428928,019-35340054

e-mail: lidiane.andrade@gmail.com

Nome completo: Daniel Capaldo Amaral

Filiação institucional: Universidade de São Paulo - Escola de Engenharia de São Carlos

Departamento: Engenharia de Produção

Função ou cargo ocupado: Professor Assistente Doutor

Endereço completo para correspondência (bairro, cidade, estado, país e CEP): Av. Trabalhador São-

Carlense, 400, Centro, São Carlos, SP, Brasil, CEP: 13566-590

Telefones para contato: (16) 3373-9433

e-mail: amaral@sc.usp.br

Recebido para publicação em: 17/04/07

Aceito para publicação em: 07/05/07 